\title{
Clinical indices and histological changes over time in ovarian torsion related to ovarian tumors
}

\author{
Mitsuru Shiota • Yasushi Kotani • Masahiko Umemoto • \\ Takako Tobiume $\cdot$ Hiroshi Hoshiai
}

Received: 10 June 2011 / Accepted: 14 October 2011 / Published online: 19 November 2011

(C) Springer-Verlag 2011

\begin{abstract}
In some emergency surgeries for ovarian torsion, the ovary cannot be conserved because of necrosis. Ovarian necrosis and the time from the onset of symptoms to surgery are likely to be directly correlated. In this study, we retrospectively evaluated the clinical indices from the time of onset of acute abdomen to surgery at our hospital, in patients with tumor-related ovarian torsion. Among cases diagnosed preoperatively with benign ovarian tumors between 1995 and 2010, there were 54 patients who developed acute abdomen that was surgically diagnosed as ovarian torsion. For evaluation, these patients were divided into two groups according to the time from the onset of acute abdomen to surgical intervention as follows: $<10$ and $\geq 10 \mathrm{~h}$. C-reactive protein (CRP) levels, leukocyte counts, body temperature, tumor size, and degree of torsion were compared between the two patient groups. Ovarian status based on postoperative histopathology was classified as necrotic, congestive, or normal, and was also evaluated. The mean CRP level was significantly higher in the $\geq 10$-h patient group than in the patients undergoing surgery in $<10 \mathrm{~h}$. No differences were observed between the two groups for leukocyte counts, body temperature, tumor size, and mean degree
\end{abstract}

\footnotetext{
M. Shiota $(\bowtie) \cdot$ Y. Kotani $\cdot$ M. Umemoto $\cdot$ T. Tobiume $\cdot$

H. Hoshiai

Department of Obstetrics and Gynecology,

Kinki University Faculty of Medicine,

377-2 Ohno-higashi, Osaka-sayama Osaka 589-8511, Japan

e-mail: shiota@med.kindai.ac.jp
}

of torsion. Ovarian necrosis was only observed only in patients undergoing surgery at $\geq 10 \mathrm{~h}$. When tumorrelated ovarian torsion is suspected, surgery should be performed within $10 \mathrm{~h}$ after the onset of acute abdomen to conserve ovarian function.

Keywords Ovarian tumor - Acute abdomen · Torsion . Emergency surgery $\cdot$ Necrosis

\section{Background}

Ovarian tumor is one of the most common gynecological diseases. Among complications of ovarian tumors, ovarian torsion causes acute abdomen and is an indication for emergency surgery. Torsion has been reported to occur in $6.9-11 \%$ of ovarian tumor patients $[1,2]$. In general, when ovarian torsion develops, venous blood flow to the ovary is first blocked, followed by abrupt onset of abdominal pain, and then, the arterial blood flow is blocked, then in some cases the ovary becomes necrotic [3] over time. In addition, ovarian tumors can rupture in some patients, resulting in peritonitis and even disseminated intravascular coagulation (DIC) [4]. In the event of necrosis, sometimes the ovary cannot be conserved and oophorectomy is required, and in other cases, even if the ovary can be conserved, ovarian function is lost. However, Mashiach et al. [5] have shown that black-blue ovaries can be preserved with no damage, maintaining future ovarian function. From the aspect of fertility, it is especially important to preserve ovarian 
function in pubescent and sexually mature patients with torsion.

Mazouni et al. reported that necrosis was significantly more frequently observed in patients undergoing surgery more than $10 \mathrm{~h}$ from the onset of abdominal pain [6]. However, there has been no definitive report on the relationship between the time to surgery and ovarian function in tumor-related ovarian torsion. In this study, we retrospectively examined patients with tumor related ovarian torsion who had undergone surgery at our hospital, and evaluated their clinical indices from the time of onset of acute abdomen until surgery.

\section{Methods}

There were 1,723 patients (1,224 laparoscopies and 499 laparotomies) who were preoperatively diagnosed with benign ovarian tumor and underwent surgery at our hospital from January 1995 to December 2010. Among these, there were 54 patients (25 laparoscopies and 29 laparotomies, 29 adnexectomies and 25 ovarian tumorectomies) who underwent surgery because of acute abdomen and who were diagnosed with tumorrelated ovarian torsion based on the intraoperative findings.

These patients were divided into the following two groups according to the time from the onset of acute abdomen to surgery: $<10$ and $\geq 10 \mathrm{~h}$ until surgery. C-reactive protein (CRP) levels (upper limit of normal, $\leq 0.3 \mathrm{mg} / \mathrm{dl}$ ), leukocyte counts (reference range, $3.5-8.5 \times 10^{3} / \mu \mathrm{l}$ ), body temperature, tumor size, and degree of torsion were compared between the two groups. The degree of torsion was estimated at $90^{\circ}$ intervals intraoperatively. Blood samples and body temperatures were obtained approximately $1 \mathrm{~h}$ before surgery.

Based on postoperative histopathological examinations of excised ovaries, the subjects were also classified into the following three groups for evaluation: a group in which necrosis was observed in at least some of the ovarian tumor tissues (Fig. 1), a group in which necrosis was not found but congestion was observed, and a normal group in which neither necrosis nor congestion was observed. The two patient groups characterized by time to surgery were compared in relation to the distribution of histopathological classifications.

For statistical analysis, the Student $t$-test was used to evaluate comparisons between the two groups. $P$ values $<0.05$ were considered statistically significant.

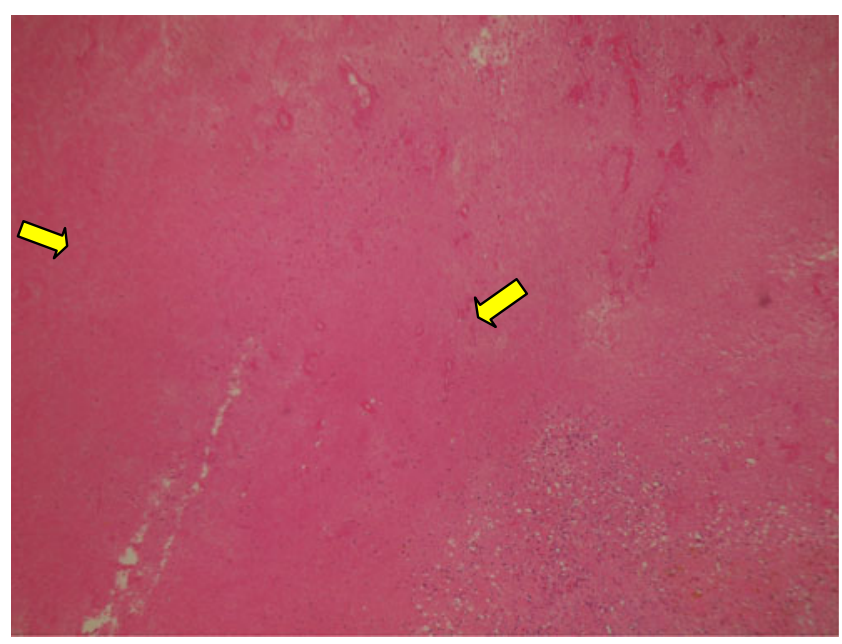

Fig. 1 Pathologic necrosis $(\mathrm{H} \& \mathrm{E}, \times 40)$

\section{Findings}

The values of the assessed parameters are shown in Table 1. The mean CRP levels in the patients who underwent surgery $10 \mathrm{~h}$ or more after symptom onset were $1.7 \mathrm{mg} / \mathrm{dl}$, and $0.1 \mathrm{mg} / \mathrm{dl}$ in patients who underwent surgery in less than $10 \mathrm{~h}$, which was significant. No differences were observed in mean leukocyte counts at $10.1 \times 10^{3} / \mu 1$ and $10.0 \times 10^{3} / \mu 1$; in mean body temperatures, at $36.7^{\circ} \mathrm{C}$ and $37.1^{\circ} \mathrm{C}$; in mean tumor sizes, at 8.3 and $9.5 \mathrm{~cm}$; and mean degrees of ovarian torsion, at $506^{\circ}$ and $667^{\circ}$, respectively, for the group of less than $10 \mathrm{~h}$ and the group of $10 \mathrm{~h}$ or more. Regarding histopathlogical findings, there were ten normal and ten congestive histological tissue specimens in the group of patients undergoing surgery less than $10 \mathrm{~h}$ after symptoms, whereas there were nine normal, 12 congestive, and 13 necrotic specimens in the patients undergoing surgery at $10 \mathrm{~h}$ or more. Necrotic ovaries were only seen in the $\geq 10$-h group. Among the 13 necrotic specimens, there were 11 with partial necrosis and two with complete necrosis, in which the entire tissue was necrotic. The delay was due to transportation from the referring clinic to our hospital (Table 2).

\section{Discussion}

Preoperative diagnosis of ovarian torsion caused by ovarian tumor is difficult, and the condition must be differentiated from other emergent gynecological diseases that present with abdominal pain, such as rupture of ovarian tumor, ovarian hemorrhage, uterine adnexitis and ectopic pregnancy. Ovarian torsion has been found 
Table 1 Comparisons of data on the two groups of patients classified by time to surgery

\begin{tabular}{lcccc}
\hline & Overall $(n=54)$ & Time $<10 \mathrm{~h}(n=20)$ & Time $\geq 10 \mathrm{~h}(n=34)$ & $P$ value \\
\hline $\mathrm{CRP}^{\mathrm{a}}(\mathrm{mg} / \mathrm{dl})$ & $1.1 \pm 2.9(0-2.9)$ & $0.1 \pm 0.3(0-1.4)$ & $1.7 \pm 3.6(0-12.9)$ & $10.0 \pm 3.2(4.2-17.3)$ \\
$\mathrm{WBC}^{\mathrm{b}}\left(10^{3} / \mu \mathrm{l}\right)$ & $10.1 \pm 3.1(3.2-17.3)$ & $10.1 \pm 2.8(4.7-13.4)$ & $37.1 \pm 0.7(35.6-38.7)$ & $\mathrm{n} . \mathrm{n}$. \\
Temperature $\left({ }^{\circ} \mathrm{C}\right)$ & $36.9 \pm 0.7(35.9-38.7)$ & $36.7 \pm 0.535 .9-37.7)$ & n.s. \\
Tumor diameter $(\mathrm{cm})$ & $9.1 \pm 3.3(3.6-20.0)$ & $8.3 \pm 2.8(4.5-15.0)$ & $667 \pm 3.6(3.6-20.0)$ & n.s. \\
Degree of torsion $\left({ }^{\circ}\right)$ & $607 \pm 309(120-1260)$ & $506 \pm 258(120-900)$ & & n.s. \\
\hline
\end{tabular}

n.s. no significant difference

${ }^{\text {a }}$ CRP upper limit of normal: $\leq 0.3 \mathrm{mg} / \mathrm{dl}$

${ }^{\mathrm{b}}$ White blood cell count reference range: $3.5-8.5 \times 10^{3} / \mu \mathrm{l}$

to represent between $2.5 \%$ and $7.4 \%$ of surgical cases of acute abdomen $[7,8]$. Thus, it is not uncommon for the diagnosis to be made only after emergency diagnostic laparoscopy $[9,10]$. Currently, there is no specific blood biomarker for tumor-related ovarian torsion [11, 12]. In suspected torsion, it is of primary importance to diagnose the torsion as soon as possible for emergent surgery, but it is also important to determine whether the affected ovary can be conserved by assessing for necrosis. However, determining the necrotic status of an ovary preoperatively is difficult. Mazouni et al. reported that necrosis was more frequently observed in cases in which more than $10 \mathrm{~h}$ had passed since the onset of abdominal pain [6]. On the other hand, Bar-On et al. reported that patients undergoing operations less than $10 \mathrm{~h}$ after admission were statistically more likely to have ovarian torsion [13]. In this study, the mean CRP level was significantly higher in the group undergoing surgery at $10 \mathrm{~h}$ or more than in the group undergoing surgery at less than $10 \mathrm{~h}$. Histologically confirmed necrosis was only observed in the group undergoing surgery at $10 \mathrm{~h}$ or more. Some studies have reported that ovarian torsion could occur following ovarian stimulation [14-16]. In this study, however, all ovarian torsion cases were associated with ovarian tumor.

Therefore, ovarian necrosis caused by ovarian torsion associated with an ovarian tumor tends to develop when more than $10 \mathrm{~h}$ have elapsed since the onset of acute

Table 2 Number of cases according to histopathological status in the two groups of patients classified by time to surgery

\begin{tabular}{llll}
\hline & $<10 \mathrm{~h}($ range $)$ & $\geq 10 \mathrm{~h}($ range $)$ & Total \\
\hline Normal & $10(3-9 \mathrm{~h})$ & $9(10-31 \mathrm{~h})$ & 19 \\
Congestive & $10(4-6 \mathrm{~h})$ & $12(10-27 \mathrm{~h})$ & 22 \\
Necrotic & 0 & $13(10-264 \mathrm{~h})$ & 13 \\
Total & 20 & 34 & 54 \\
\hline
\end{tabular}

abdomen, and development of necrosis leads to an elevated CRP level. The results of this study also indicate that if ovarian torsion is suspected, surgery should be performed as soon as possible at least within $10 \mathrm{~h}$ after the onset of acute abdomen to conserve ovarian function. In our hospital, surgery is performed promptly for an inpatient when ovarian torsion is suspected. The cases that were delayed were primarily those cases transported from other hospitals. Therefore, if the hospital does not have the appropriate operating facilities, prompt arrangement of transportation is necessary for a patient with suspected ovarian torsion.

\section{Conclusion}

In all the cases in this study that were classified in the necrotic group for evaluation, necrosis was seen in least a part of the tissue specimen. Although we cannot conclude from our findings that ovarian function would be lost in every patient in the necrotic group, if torsion is suspected, we believe that immediate action is necessary to preserve ovarian function. Also, in any cases where the torsion is suspected, surgery should be performed as soon as possible.

The limit of this present study is that $10 \mathrm{~h}$ was taken as cut-off reference time on the basis of the result indicated in the study by Mazouni et al. However, time to surgery is a continuous variable, and the cases should have been investigated at different time points especially regarding the torsion of ovary. We will address this issue more precisely in the future study, taking the time parameter as a continuous variable.

Conflicts of interest The authors report no conflicts of interest. The authors alone are responsible for the content and writing of the paper. 


\section{References}

1. Lee CH, Raman S, Sivanesaratnam V (1989) Torsion of ovarian tumors: a clinicopathological study. Int J Gynaecol Obstet 28:2125

2. Sommerville M, Grimes DA, Koonings PP, Campbell K (1991) Ovarian neoplasms and the risk of adnexal torsion. Am J Obstet Gynecol 164:577-578

3. Nichols DH, Julian PJ (1985) Torsion of the adnexa. Clin Obstet Gynecol 28:375-380

4. Ishikawa M, Tamate K (1999) Comprehensive handbook of women's medicine 8. In: Taketani Y (ed) Emergency gynecologic and obstetric cases. Nakayama Shoten, Tokyo, p 40

5. Mashiach S, Bider D, Moran O, Goldenberg M, Ben-Rafael Z (1990) Adnexal torsion of hyperstimulated ovaries in pregnancies after gonadotropin therapy. Fertil Steril 53:76-80

6. Mazouni C, Bretelle F, Ménard JP, Blanc B, Gamerre M (2005) Diagnosis of adnexal torsion and predictive factors of adnexal necrosis. Gynecol Obstet Fertil 33:102-106 (in French)

7. Hibbard LT (1985) Adnexal torsion. Am J Obstet Gynecol 152:456-461

8. Anteby SO, Schenker JG, Polishuk WZ (1975) The value of laparoscopy in acute pelvic pain. Ann Surg 181:484-486
9. Mage G, Canis M, Manhes H, Pouly JL, Bruhat MA (1989) Laparoscopic management of adnexal torsion. A review of 35 cases. J Reprod Med 34:520-524

10. Porpora MG, Gomel V (1997) The role of laparoscopy in the management of pelvic pain in women of reproductive age. Fertil Steril 68:765-779

11. Chiou SY, Lev-Toaff AS, Masuda E, Feld RI, Bergin D (2007) Adnexal torsion: new clinical and imaging observations by sonography, computed tomography, and magnetic resonance imaging. J Ultrasound Med 26:1289-1301

12. Descargues G, Tinlot-Mauger F, Gravier A, Lemoine JP, Marpeau L (2001) Adnexal torsion: a report on forty-five cases. Eur J Obstet Gynecol Reprod Biol 98:91-96

13. Bar-On S, Mashiach R, Stockheim D et al (2010) Emergency laparoscopy for suspected ovarian torsion: are we too hasty to operate? Fertil Steril 93:2012-2015

14. Bider D, Mashiach S, Dulitzky M, Kokia E, Lipitz S, Ben-Rafael Z (1991) Clinical, surgical and pathologic findings of adnexal torsion in pregnant and nonpregnant women. Surg Gynecol Obstet 173:363-366

15. Oelsner G, Bider D, Goldenberg M, Admon D, Mashiach S (1993) Long-term follow-up of the twisted ischemic adnexa managed by detorsion. Fertil Steril 60:976-979

16. Shalev E, Peleg D (1993) Laparoscopic treatment of adnexal torsion. Surg Gynecol Obstet 176:448-450 